\title{
First aid and resuscitation knowledge among laypeople with driving licence in Hungary
}

Balint Banfai', Nora Horvath², Attila Pandur', Krisztina Deutsch'1, Balazs Radnai', Henrietta Csonka ${ }^{3}$, Jozsef Betlehem

1 University of Pécs, Faculty of Health Sciences, Institute of Emergency Care and Health Pedagogy, Pécs, Hungary

2 National Ambulance Service, Siklós, Hungary

3 University of Pécs, Department of Emergency Medicine, Pécs, Hungary

\section{Purpose of the study:}

In Hungary, 26.000 people die due to sudden cardiac death every year. Usually, participating in a first aid training is possible for laypeople in Hungary only, when they want to obtain a driving licence.

Our aim was to assess the effectiveness of first aid training captured to the driving licence.

\section{Material and methods:}

102 people $(\mathrm{N}=102)$ with driving licence were involved in this cross-sectional study in Baranya county, Hungary. A self-fill-in questionnaire was used to collect data.

The research tool consisted of demographic data, solving first aid situations, overal satisfaction with first aid courses and suggestions.

Descriptive statistics, Chi-square-test, t-tes were used for statistical analyses with help of SPSS 22.0.

Results were considered significant in case of $p<0.05$.

\begin{tabular}{|l|l|l|l|}
\hline \multirow{3}{*}{ Gender: } & Men & $54,90 \%$ & $\mathrm{n}=56$ \\
\cline { 2 - 4 } & Women & $45,10 \%$ & $\mathrm{n}=46$ \\
\hline \multirow{5}{*}{ Location: } & Pécs & $14,70 \%$ & $\mathrm{n}=15$ \\
\hline & Other city & $51,00 \%$ & $\mathrm{n}=52$ \\
\hline & Village & $34,30 \%$ & $\mathrm{n}=35$ \\
\hline & $\mathbf{1 7 - 2 2}$ years & $29,40 \%$ & $\mathrm{n}=30$ \\
\hline & $\mathbf{2 3 - 2 9}$ years & $30,40 \%$ & $\mathrm{n}=31$ \\
\hline & $\mathbf{3 0 - 4 0}$ years & $22,50 \%$ & $\mathrm{n}=23$ \\
\hline & $\mathbf{4 0}$ years & $17,60 \%$ & $\mathrm{n}=18$ \\
\hline \multirow{5}{*}{ Educational attainment: } & Primary school & $13,70 \%$ & $\mathrm{n}=14$ \\
\cline { 2 - 4 } & Highschool/Secondary school & $61,80 \%$ & $\mathrm{n}=63$ \\
\hline & University/College & $24,50 \%$ & $\mathrm{n}=25$ \\
\hline & $<1$ year & $17,60 \%$ & $\mathrm{n}=18$ \\
\hline & $\mathbf{1 - 2}$ years & $6,90 \%$ & $\mathrm{n}=7$ \\
\hline & $\mathbf{3 - 5}$ years & $20,60 \%$ & $\mathrm{n}=21$ \\
\hline & $\mathbf{5}$ years & $54,90 \%$ & $\mathrm{n}=56$ \\
\hline
\end{tabular}

The main demographic data $(\mathrm{N}=102)$

\section{Results:}

Regarding the first aid knowledge, participants reached 4.16 points on average $(S D=1.9)$ out of 10 points.

There was no significant difference between men and women $(p=0.69)$.

Knowledge with training within one year was significantly better in the following six professional issues: examination of breathing $(p<0.01)$, ratio of chest compression and ventilation $(p<0.01)$ during $C P R$, conditions of resuscitation $(p<0.01)$, safety $(p=0.023)$ foreign body in airways (0.015), treating broken legs $(p=0.025)$.

Based on the answers the best options for learning first aid would be schools and workplaces $(70.6 \%)$

$84.3 \%$ of the participants would like to participate on a refreshing first aid course.

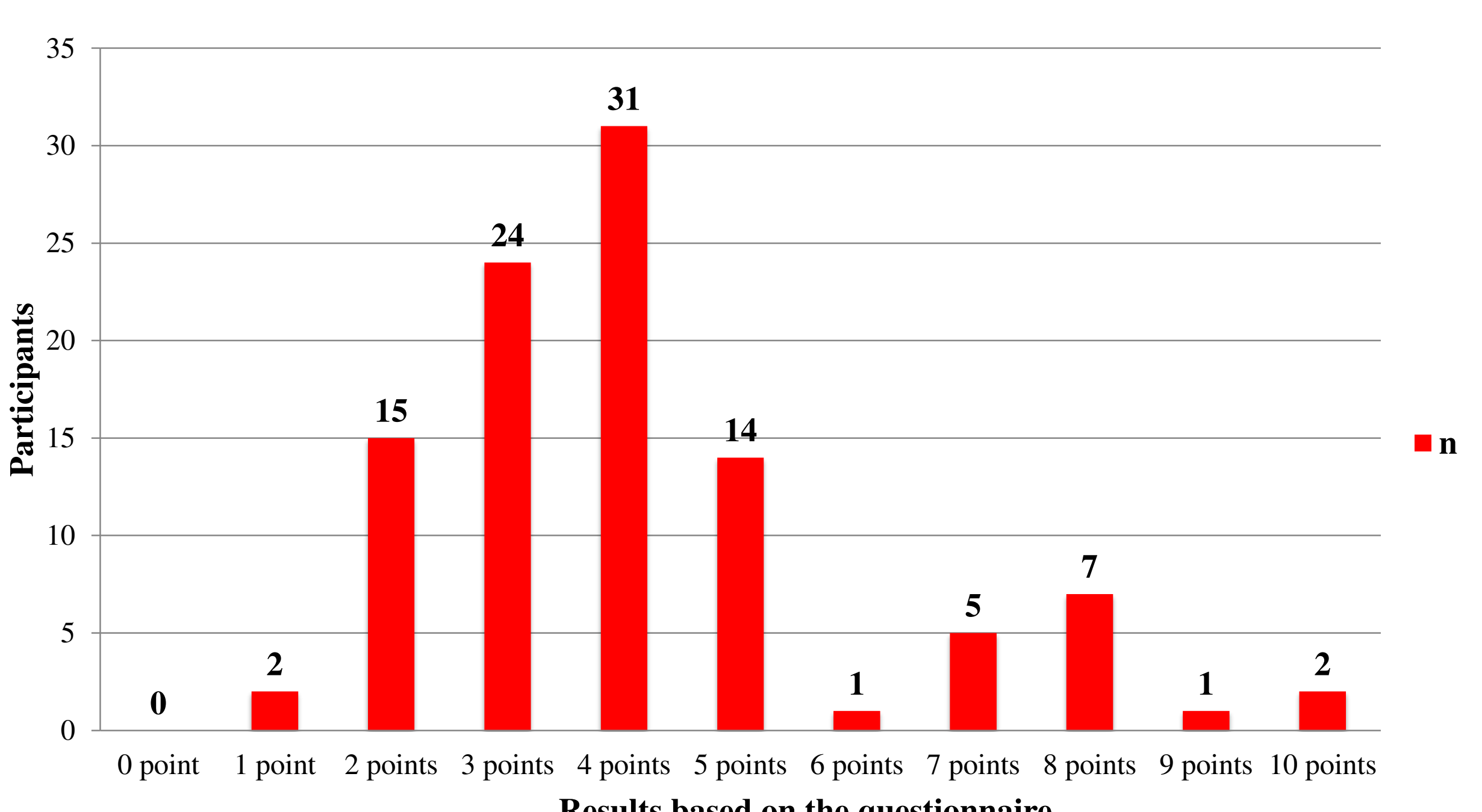

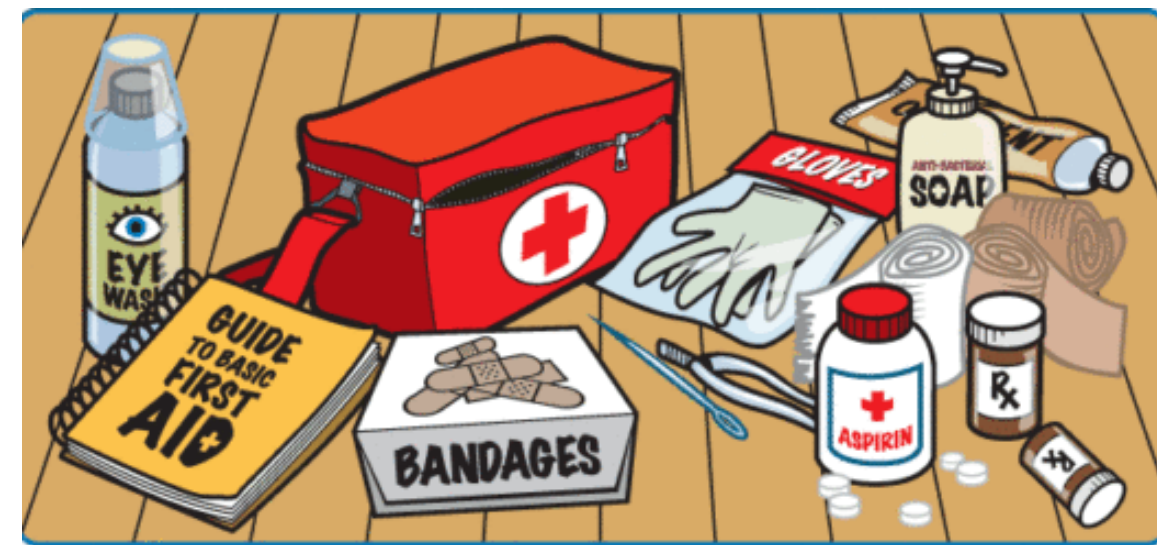

\section{Conclusions:}

Laypersons' first aid knowledge seems not to be appropriate enough more than one year after training.

People require available first aid courses (in schools and workplaces) to improve their knowledge.

This survey assessed the theoretical first aid knowledge only so it would be required to examine the practical skills of laypersons. 